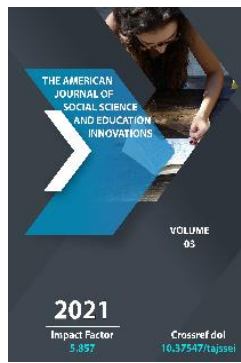

\title{
Social Psychological Characteristics Of Adolescents Who Have Committed Suicide Attempts
}

\author{
Tukhtakhon Gaynazarovna Suleymanova \\ PhD In Psychology, Associate-Professor At The Department "General Psychology" of \\ Andizhan State University, Andizhan Region, Republic Of Uzbekistan
}

Journal Website:

https://theamericanjou

rnals.com/index.php/ta

jssei

Copyright: Original content from this work may be used under the terms of the creative commons attributes 4.0 licence.

\section{ABSTRACT}

The article analyzes the approaches aimed at studying the determinants of social and individual psychological factors that lead to suicidal attempts during adolescence. It also classifies the traumatic effects of social psychological factors that lead to suicidal ideation during adolescence. It should be noted that the role of interpersonal and family relationships in the manifestation of suicidal behavior in adolescents is high. Information about a person's unconscious tendencies can be obtained by studying the characteristics of suicides left before death. According to the researchers, the common feature for them is that the text occupies the entire width of the page, the side lines are small or absent, the lines are not separated from each other.

\section{KEYWORDS}

Adolescence, adaptation, crisis, destructive behavior, emotional disorders, suicide, antivital experiences, communication.

\section{INTRODUCTION}

On the one hand, suicide is a social phenomenon related to the structure of society, as a phenomenon of consciously putting an end to one's life only inherent in man. On the other hand, it is an individual's reaction to a difficult situation (psychological crisis) arising from the characteristics of a particular individual [12]. Suicidal behavior is formed as a result of adolescents' responsiveness to destructive situations in destructive ways. Therefore, in determining the risk of suicide, it is necessary to conduct a 
rapid diagnosis of psychological characteristics of adolescents who have committed suicide, emotional disorders in adolescents, antivital experiences and conflicts in areas of importance to the adolescent, according to many researchers [9].

\section{METHODS}

Some authors [1,7] based on interviews and clinical materials with adolescents who have attempted suicide, concluded that there is no typical situation that manifests itself as a suicidal personality structure or a form of suicide resolution. Despite this view, other researchers cite the psychological characteristics of suicides. The manifestation of relatively direct, subconscious and noncognitive individual-individual features can be determined using projective methods. In particular, in test methods such as "Image of Man”, "House-Tree-Man", “Non-existent creature", all movements manipulated by the neck as a center of conflict are a serious factor in suicide [18]. According to A.G. Ambrumova and O.Kalashnikova, suicides often choose purple in the first position based on the "Color Choice Method" color test, which reflects the difficulties in social adaptation associated with a person's individuality, attitudes, interests, and actions. The preference for purple in the selection process indicates the relative lability of affect, expressing the predominance of mental stress, guilt, obedience, and hope [1].

\section{RESULTS AND DISCUSSIONS}

According to G.A.Fastovtsev [14], a passivedefensive position disharmonious person in suicides according to the Luscher method, frustrated need for warm interpersonal relationships, rejection of others and a tendency to evaluate the situation with a fictitious tendency to self-esteem, internal conflict, contradiction, the presence of a high level of anxiety. It should be noted that the role of interpersonal and family relationships in the manifestation of suicidal behavior in adolescents is high. Information about a person's unconscious tendencies can be obtained by studying the characteristics of suicides left before death. According to the researchers, the common feature for them is that the text occupies the entire width of the page, the side lines are small or absent, the lines are not separated from each other. The initial is characterized by uniformity, parallelism of the core, solid pressure, stability of the main line. These characteristics are consistent with sensory perception, which, unlike intuitive perception, is characterized by the perception of the concrete world at the present time. If sensory perception takes precedence in assessing reality, but in reality the situation is bad, despair is easily felt $[2,6,8]$. During the implementation of the method of "counting the time interval", a steady acceleration of the rate of minute measurement was observed in individuals who committed suicide [2]. According to Yu.R.Vagin, more than doubling the response time to death-related words during the "Associative Test" led to the conclusion that the subjects showed severe pathological levels of avital activity, although they were not fully understood by them [4].

A.G. Ambrumova and her co-authors highlight the peculiar intellect of suicides, noting that in one case it was a stable feature of the psyche, while in another it manifested itself in the period of special circumstances. However, the authors did not specify the reasons for this peculiarity [1]. B.M. Umarov's research work "Age and social psychological features of suicide in children and adolescents" proved that there is no correlation between suicidal behavior and intellectual development [7]. Individuals with suicidal tendencies were found to have higher levels of anxiety using MMPI and Spielberger-Hanin's "self-assessment scale" methodologies. According to O. Yu. Stepanchenko [13], based on the "Tomsk rigidity survey", it was determined that mental rigidity is a constant component of the structure of the suicidal person. At the same 
time, high rates are individual risk factors that trigger a person's suicidal behavior under stress. These features can serve as a differential-diagnostic and prognostic criterion of suicide risk.

A number of authors have noted the presence of impulsivity in the personality structure of suicides [1]. Suicide is characterized by a relatively external locus - a manifestation of control [14]. Suicidal people do not take responsibility for their actions, as well as the events that take place in their lives, but blame it on fate, coincidence other people. An important symptom of suicide is ambivalence, which makes it difficult to determine true intentions. That's why sometimes people who try to commit suicide say, "It doesn't look like depression. He was in a very good mood last night"[13].

A.G. Ambrumova and E.M. Vrono [1], based on a study of personality traits of suicidal adolescents, found that many of them were characterized by impulsivity, a certain exploitativeness and emotional instability, often manifested in inability to think about decisions, which often resulted in conflict situations ending in suicidal behavior explained. In many cases, the loss of a close relationship, which is important for adolescents, can lead to cases of mental trauma. In this case, the inner world of the teenager is "destroyed". Behind the selfconfident appearance of the real "l" is a gentle soul. In this case, the use of the phrases "Time heals everything", "There are other girls or boys" will not comfort the teenager. The betrayal of a loved one, rude treatment can lead to serious mental injury.

Suicidal risk is characterized by low self-esteem [6], a tendency to self-blame, extreme emotionality, helplessness, and a lack of selfconfidence in a positive correlation with pessimistic attitudes toward the future, egocentrism, is associated with mistrust and paranoia of the suicidal person [13].
Throughout his life, a person repeatedly encounters difficult situations, job changes, serious illnesses, family crises, and more. These experiences can not only cause emotional stress, but also have a long-term cumulative effect on a person's physical and psychological health. Usually a person tries to overcome life difficulties without becoming passive in a situation. The method of attempting to overcome implies the ability of the individual to adapt to destructive influences [3]. The search strategy is also determined by the subject's personality traits, his life experience, emotional state, understanding of the importance of the situation and the way out of such situations known to him $[1,5]$.

Suicidal people are characterized by a subjective reassessment of the complexity of the conflict situation, a sense of helplessness, a firm belief in the insolvency of their problems in the imaginary options for overcoming the crisis.

Suicides are characterized by difficulty in expressing will, difficulty in making decisions, and boredom [5]. Another characteristic of suicides is the loss of activity in situations of stress and frustration, a decrease in confidence in the future [7]. It can be seen that suicidal behavior manifests itself through identification, i.e. as an imitation phenomenon associated with a tendency to imitate [13]. Some researchers have seen a worrying increase in suicides among adolescents in recent years due to the fact that in practice adolescents are dissatisfied with today's heroes offered by modern culture [15]. Materials on television, Internet sites, and other media, the main topic of which is suicide, indirectly lead to an increase in the number of suicides among adolescents [3, 4].

The lower the understanding of life, the less a person is focused on solving problems directly in difficult situations, the less he takes responsibility for what happened, the less active action and the desire to correct the 
situation. In adolescents, feelings of secondarily, dissatisfaction with social status, and increased likelihood of suicidal thoughts and attempts occur. The place in communication can be described as strong and weak depending on how communicative the person is and how satisfied he or she is with his or her place in the communication system.

Having a place in communication depends on the person, his psyche and ability to adapt to others, his conscious effort to achieve the desired relationship, and the value that the individual gives to those around him. First of all, it should be noted that a teenager is not always able to understand what kind of action is expected of him by those around him [4]. The level of self-satisfaction depends on what the adolescent is interested in communicating, what he or she is focused on, what he or she is trying to avoid, and in what environment he or she is able to achieve it should be focused.

Thus, an increase in the amount of suicidal behavior is observed from childhood to adolescence. At the same time, adolescence is associated with changes in the organism puberty and adolescent autonomy. At this stage, the pace of development is rapid, and significant changes are observed in the field of personality formation. Adolescents often feel lonely and dissatisfied with themselves and those around them, although relationships with adults and peers often seem desirable from the outside [4.2]. The teenager strives to have a close, trusted friend and quickly replaces his friends. Usually he seeks in his friend similarity, understanding, acceptance of his personal experiences and attitudes. A friend not only understands himself well, but also helps him to feel self-doubt, to overcome doubts about his own values, to feel himself as a person [12].

Thus, it can be concluded that perceptions of the psychological characteristics of adolescents who have attempted suicide are manifested in the following: $[1,6,9]$.
- Although there is no single view that suggests that there is a specific personality structure that suicidal tendencies or typical situations characterized as a form of suicide resolution, most researchers cite (based) psychological characteristics of suicides;

- Suicidal people are characterized by stress, impulsivity, emotional instability, high exposure, imitation of collections in literature and cinema, easy access to the image, the desire to build their behavior like the heroes of books and movies;

- The aspirations of suicides are often associated with suicide, revenge, punishment, reunification, and rebirth;

- The higher the tendency to suicide in adolescents, the more they feel negative about their bodies, they perceive it without being connected to each other;

- Suicidal models are easily mastered in socially immature adolescents, among whom are adolescents who are devoted to the acquisition of very new behavioral patterns;

- No correlation was found between the level of intelligence and suicide;

- To assess the risk of social maladaptation and the possibility of suicide, it is necessary to identify a set of symptoms in family diagnosis and pay attention to how they are combined.

It has been observed that television programs, websites and other media materials, the main topic of which is suicide, indirectly lead to an increase in the number of suicides among adolescents. [12]. Among them, adolescents who are committed to learning very new behavioral patterns stand out [10].

\section{CONCLUSION}

Among the cases of suicide among adolescents, the factor of love, that is, the loss of a loved one, the factor of infidelity also plays an important role. In articles published in some entertaining newspapers and magazines, a 
young man or woman commits suicide at the end of a love affair before a solution can be found.

A guy or a girl prefers death to fighting for their own happiness. However, in "Last Days", which has been loved and read by many generations, Silver does not die by drinking poison, but by Zaynab. From beginning to end, the work encourages young men and women to fight for their own happiness. Unfortunately, stories in newspapers and magazines about the sudden emotional breakdown of a boy and a girl, betrayal, suicide by parents, misunderstandings by others, and consequent remorse from others, become an indirect source of suicidal activity for a teenager in crisis. Information on various methods and means of suicide, rituals on the Internet sites are becoming a direct motivator for suicide in adolescents in crisis. The high level of importance of such negative factors for adolescents justifies the need to include them in the plan of psychoprophylactic measures carried out among adolescents.

\section{REFERENCES}

1. Ambrumova A.G., Tixenko V.A. Diagnosis of suicidal behavior // $M$ : Ministry of Health, $1990 .-106$ p.

2. Bubnov V.G., Bubnova N.V. How to prevent suicide. - $M$.: Publishing house “Halo", 1994. - 15 p.

3. Vasilchenko M.V. "Psychological support of adolescents at risk, prone to crisis states and suicidal behavior". Moscow.

4. Vrono E.M. Unhappy Children - Difficult Parents: Observations of a Child Psychiatrist. - M: Family and school, 1997.$108 \mathrm{p}$.

5. Gilinsky Ya.I., Afanfsyev V.S. Sociology of deviant (deviant) behavior. Textbook. allowance. - SPb: SPb branch of IS RAS, $1993 .-248 \mathrm{p}$.

6. Grollman E. Suicide: prevention, intervention, postventia // Suicidology: past and present: The problem of suicide in the works of philosophers, sociologists, psychotherapists and in literary texts. - M: "Kogito-Center", 2001. - p. 270 - 353.

7. Umarov B.M. Age and socio-psychological characteristics of child and adolescent suicide: Ph.D dissertation in Psychology. Tashkent: TDPI, 1993. - $154 \mathrm{p}$.

8. K.Farfieva.TV shows on the change of behavior of young people. T, 2015.

9. Frankl V, Psychotherapy in practice. SPb .: «Juventa», 1999. -256 p.

10. Erikson E. Childhood and society. SPb: ITD «Letniy sad», 2000. - 416p.

11. Yureva L.K Crisis situation. Dnepropetrovsk: Art-Press, 1998. -156 p.

12. Eydemiller E.G., Yustitskiy V.V. Semeynaya psychotherapy.

13. Psychology and psychotherapy semi, - 3-e pub. - SPb .: Peter, 2001. - 656 p.

14. Yakovleva S.T. Suicidal attempts by selfpoisoning: epidemiological, toxicological and clinical aspects: Abstract. dis. ... cand. med. sciences. -M., $2000-20$ p. 